\title{
A Study of Prognostic Significance of Perineural Invasion in Oral Squamous Cell Carcinoma
}

\author{
Zubair Durrani (FFDRCD, FRCS, FRCS (OMFS)) $)^{1^{*}}$, Sahar Khalid (BDS) ${ }^{2}$, Omer Bashir (BDS, FCPS (pk)) ${ }^{3}$ and \\ Khyzran Khan (BDS) ${ }^{4}$ \\ ${ }^{1}$ Consultant, Oral and maxillofacial surgery dept, Rehman Medical Institute, Pakistan
}

${ }^{2}$ Training Medical Officer, Oral and Maxillofacial Surgery dept, Rehman medical institute, Pakistan

${ }^{3}$ MOMS RCS Edinburgh, UK

${ }^{4}$ Intern, Oral and Maxillofacial dept, Rehman medical Institute, Pakistan

*Corresponding author: Zubair Durrani (FFDRCD, FRCS, FRCS (OMFS)), Consultant, Oral and maxillofacial surgery dept, Rehman Medical Institute, Pakistan.

Received Date: January 11, 2021

Published Date: March 24, 2021

\begin{abstract}
Objective: To measure the frequency of perineural invasion in oral squamous cell carcinoma, to correlate its presence with various variables and to assess its impact upon prognosis.

Design: A retrospective analytical study was planned.

Place and Duration of study: Patients were identified with oral squamous cell carcinoma who had underwent surgical excision over the past 7 years in Rehman Medical institute. The duration of the study was 6 months.

Methodology: Pathology reports were collected; and based upon the presence or absence of PNI, Patients were divided in to two groups. The group with PNI were analyzed for a set of associations and then compared with other group for comparison. PNI frequency was correlated with age, gender, site, size and differentiation of tumor. Presence of PNI, number of tumor foci along the perineural region and the size of nerve involved were then correlated with presence or absence with nodal disease and frequency of recurrence in these cases. Results were compiled and statistically analyzed using chi square test.

Results: Total number of Patients included in study were 59. PNI was found present in 13 (22.03\%) patients. PNI was found mainly in middle age group. Gender distribution: male-7, female-6 ( $\mathrm{p}=0.454)$; Site distribution; Tongue carcinoma-6, other sites-7 ( $\mathrm{p}=0.618)$; Size: T3-10, T1-3 $(\mathrm{p}=0.330)$; Differentiation: well differentiated-10, Moderate Differentiated-3 ( $\mathrm{p}=0.197)$. Association of nodal status with PNI found positive in 6 patients $(\mathrm{p}=0.000)$. Association of recurrence with PNI was also found positive in 6 patients $(\mathrm{p}=0.001)$. Number of foci of perineural invasions $(1$ focus-7, 11 foci- 1 , 3 foci- 3,4 foci- 1,5 foci- 1 ) association with recurrence ( 6 cases) $p=0.535$ and lymph node metastasis ( 6 cases) $p=0.490$. Nerve size involved by PNI ( $<1 \mathrm{~mm}-3,>1 \mathrm{~mm}-10)$ association with either lymph node metastasis (6) p=0.672 or recurrence in the neck (6) p=0.417.

Conclusion: The frequency of PNI was $22.03 \%$. Statistically, no significant association was found between PNI and age, gender, site, grade of tumor and size of the tumor. Significant Association was found in this study between occurrence of PNI with Lymph Node metastasis and Neck Recurrence. No Significant Association was found between number of foci of Perineural invasions or the size of the nerve involved with either lymph node metastasis or recurrence.
\end{abstract}

Keywords: Perineural invasion; Oral squamous cell carcinoma; Prognostic factors

\section{Introduction}

Cancer of the oral cavity is a widely prevalent disease and has been listed as the sixth most common cancer worldwide [1]. Squamous cell carcinoma (SCC) accounts for about $90 \%$ of all these cases [2]. Despite tremendous research over the last 70 years, the overall prognosis remains at $50 \%$ with no gender difference [3]. The incidence, however, is higher in men than women according to
WHO data. Prognostic factors include tumor stage, grade, depth of invasion and lymph node involvement. One of the factors which has a prognostic significance but less well studied is perineural invasion (PNI). The aim of this study was to measure the frequency of PNI in our set of oral squamous cell carcinoma patients. Various variables including age, gender, site, size, grade of the tumor was correlated 
with PNI for their impact upon its incidence. The presence of PNI, size of the nerve involved and tumor focality were then studied for its relation with nodal metastasis and loco-regional recurrence.

\section{Methodology}

A retrospective analytical study was planned. Patients were identified with oral squamous cell carcinoma that had undergone surgical resection over the past 7 years in Rehman Medical institute. Pathology reports were collected, and based upon the presence or absence of PNI, Patients were divided into two groups. The group with PNI were analyzed for a set of associations mentioned above. Presence of PNI, number of tumor foci along the perineural region and the size of nerve involved by PNI were then correlated with presence or absence with nodal disease and frequency of recurrence in these cases. Results were compiled and statistically analyzed using chi square test.

\section{Table 1}

\begin{tabular}{|c|c|}
\hline Clinicopathological Characteristics of $59 \mathrm{~F}$ & \\
\hline & No of patients \\
\hline \multicolumn{2}{|l|}{ T stage } \\
\hline $\mathrm{T} 1$ & 25 \\
\hline $\mathrm{T} 2$ & 7 \\
\hline T3 & 27 \\
\hline $\mathrm{T} 4$ & 0 \\
\hline \multicolumn{2}{|l|}{ N stage } \\
\hline $\mathrm{PNx}$ & 42 \\
\hline PNo & 6 \\
\hline PN2b & 11 \\
\hline \multicolumn{2}{|l|}{ Differentiation } \\
\hline Well & 53 \\
\hline Moderate & 6 \\
\hline \multicolumn{2}{|c|}{ Perineural invasion } \\
\hline Present & 13 \\
\hline Absent & 46 \\
\hline \multicolumn{2}{|l|}{ Nerve size } \\
\hline$<1 \mathrm{~mm}$ & 3 \\
\hline$>1 \mathrm{~mm}$ & 10 \\
\hline \multicolumn{2}{|l|}{ Tumor foci } \\
\hline 1 & 7 \\
\hline 2 & 1 \\
\hline 3 & 3 \\
\hline 4 & 1 \\
\hline 5 & 1 \\
\hline \multicolumn{2}{|l|}{ Recurrence } \\
\hline Present & 10 \\
\hline Absent & 31 \\
\hline Untraceable & 18 \\
\hline
\end{tabular}

\section{Results}

Total number of Patients operated for oral squamous cell carcinoma were 59. PNI was found to be present in 13 (22.03\%) patients. Overall age range for all SCC patients was from 28 to 89 (Figure 1) while SCC with PNI were found between 28 to 75 years of age with mean of 48.2 and median of 46 respectively (Figure 2). Out of 13 patients with PNI, there were seven males and six females effected. Tongue was the most common site of presentation with 6 patients followed by Maxillary and mandibular alveolar gingiva effecting two patients each. There was a single presentation each for lip, buccal mucosa and neck (unknown primary). Three patients had presented with T1 and ten with T3 size. Ten patients were well differentiated while three were moderately differentiated. The patient's characteristics and pathologic findings are summarized in (Table 1). 
Table 2

\begin{tabular}{|c|c|c|c|c|c|c|c|}
\hline Relationship between nerv & nd clinicopat & \multicolumn{4}{|c|}{ Focci } & & \multirow{2}{*}{ Chi square test $P$ value } \\
\hline Factors & & 1 & 2 & 3 & 4 & 5 & \\
\hline \multirow{3}{*}{ Recurrence } & Present & 4 & 1 & 1 & 0 & 0 & \multirow{3}{*}{0.535} \\
\hline & absent & 0 & 0 & 1 & 0 & 0 & \\
\hline & Untraceable & 3 & 0 & 1 & 1 & 1 & \\
\hline \multirow{2}{*}{ Metastatic lymph nodes } & $\mathrm{PNx}$ & 3 & 0 & 2 & 1 & 1 & \multirow{2}{*}{0.49} \\
\hline & PN2b & 4 & 1 & 1 & 0 & 0 & \\
\hline
\end{tabular}

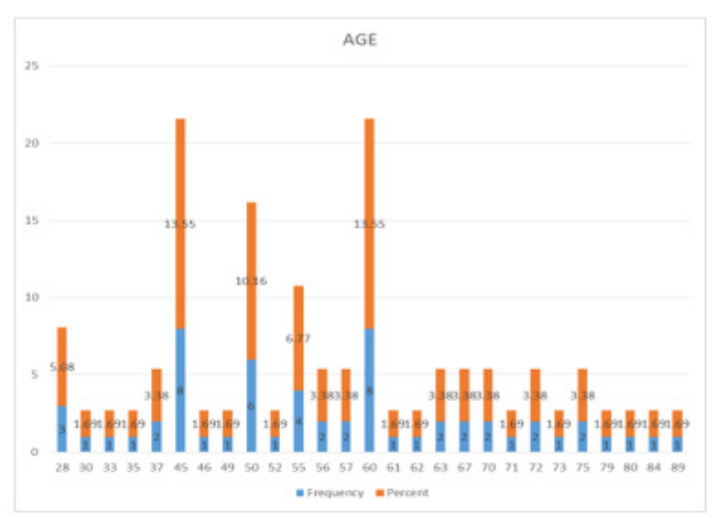

Figure 1

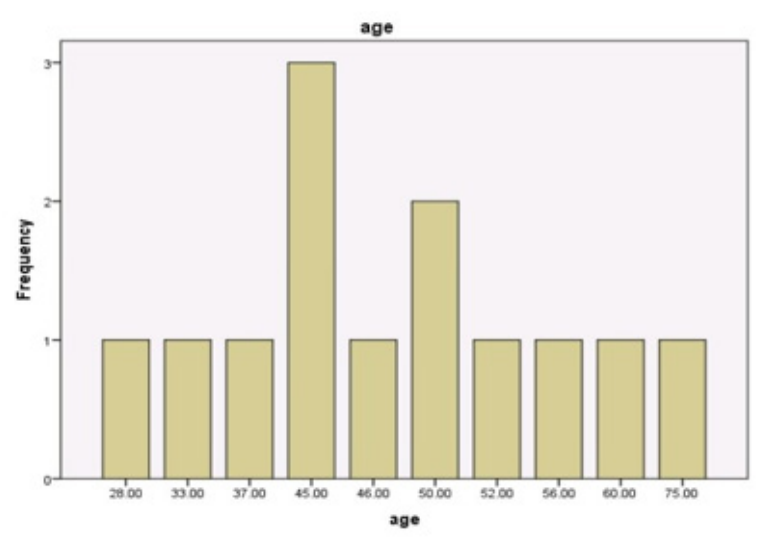

Figure 2

Six patients of PNI presented with pathologically involved lymph nodes. This association between PNI and lymph node involvement by tumor was found to be statistically significant on Pearson chi-square test $(\mathrm{p}=0.000)$. Four patients with one PNI focus developed metastatic lymph node. One patient who had two and another who had three PNI foci had positive metastasis lymph nodes; while patients with four and five PNI foci developed no lymph node metastasis. This association was again found statistically insignificant $(p=0.490)$ (Table 2). Lymph node metastasis was found in four patients with nerve size greater than $1 \mathrm{~mm}$ and in two patients with nerve size less than $1 \mathrm{~mm}$. This association statistically was also insignificant $(\mathrm{p}=0.416)$.

Out of 7 patients who developed locoregional recurrence, 6 patients had PNI. This association was again found to be statistically significant ( $\mathrm{P}=0.001$ ) (Table 3 ). Out of these six patients, four had one focus of PNI, one had two and another one patient with three foci had recurrence. None of the patients of four and five foci developed recurrence. This association between PNI focality and recurrence was found to be statistically insignificant $(\mathrm{p}=0.535)$. Recurrence was found in four patients with nerve size greater than $1 \mathrm{~mm}$ and in two patients with nerve size less than $1 \mathrm{~mm}$. This association was statistically not significant $(\mathrm{p}=0.672)$ (Table 4$)$. 
Table 3

\begin{tabular}{|c|c|c|c|}
\hline \multicolumn{4}{|c|}{ Relationship between PNI and Clinicopathalogical Factors } \\
\hline \multirow{2}{*}{ Factors } & \multicolumn{2}{|c|}{ PNI } & \multirow{2}{*}{$P$ value } \\
\hline & Present & Absent & \\
\hline \multicolumn{4}{|l|}{ Site } \\
\hline Face & 0 & 1 & \multirow{7}{*}{0.618} \\
\hline Lips & 1 & 11 & \\
\hline Mandible & 2 & 7 & \\
\hline Maxilla & 2 & 3 & \\
\hline Mucosa & 1 & 7 & \\
\hline Neck & 1 & 2 & \\
\hline tongue & 6 & 15 & \\
\hline \multicolumn{4}{|l|}{ Gender } \\
\hline Male & 7 & 30 & \multirow{2}{*}{0.454} \\
\hline Female & 6 & 16 & \\
\hline \multicolumn{4}{|l|}{ T stage } \\
\hline $\mathrm{T} 1$ & 3 & 22 & \multirow{3}{*}{0.33} \\
\hline $\mathrm{T} 2$ & 0 & 7 & \\
\hline $\mathrm{T} 3$ & 10 & 17 & \\
\hline \multicolumn{4}{|c|}{ Histological Differentiation } \\
\hline Well & 10 & 43 & \multirow{2}{*}{0.197} \\
\hline Moderate & 3 & 3 & \\
\hline \multicolumn{4}{|l|}{ Nodal Status } \\
\hline $\mathrm{PNx}$ & 7 & 35 & \multirow{3}{*}{0} \\
\hline PNO & 0 & 6 & \\
\hline $\mathrm{PN} 2 \mathrm{~b}$ & 6 & 5 & \\
\hline \multicolumn{4}{|l|}{ Recurrence } \\
\hline present & 6 & 4 & \multirow{3}{*}{0.001} \\
\hline absent & 1 & 30 & \\
\hline untraceable & 6 & 12 & \\
\hline
\end{tabular}

\section{Table 4}

\begin{tabular}{|c|c|c|c|c|}
\hline \multicolumn{5}{|c|}{ Relationship Between Nerve Size and Clinicopathological Factors } \\
\hline \multirow{2}{*}{ Factors } & & \multicolumn{2}{|c|}{ Nerve size } & \multirow{2}{*}{ Chi square test $P$ value } \\
\hline & & $<1 \mathrm{~mm}$ & $>1 \mathrm{~mm}$ & \\
\hline \multirow{3}{*}{ Recurrence } & Present & 2 & 4 & \multirow{3}{*}{0.672} \\
\hline & Absent & 0 & 1 & \\
\hline & Untraceable & 1 & 5 & \\
\hline \multirow{2}{*}{ Metastatic lymph nodes } & $\mathrm{PNx}$ & 1 & 6 & \multirow{2}{*}{0.416} \\
\hline & PN2b & 6 & 4 & \\
\hline
\end{tabular}

\section{Discussion}

Historically, the definition of PNI has changed over the last 35 years. Batsakis in 1985 defined PNI as tumor cells that invade in, around and through the nerves [4]. In 2009 Liebig, et al [4] stated that if the tumor cells were found in close proximity to the nerve and involved at least 33\% of its circumference or if the tumor cells were found within any of the three layers of nerve sheath i.e., epineurium, perineurium or endoneurium, it should be considered as perineural invasion [4]. Versha, et al. [5] in a case series of 117 patients defined PNI as tumor cells that invades the perineurial space or epineurium [5]. PNI was initially thought to spread via perineurium or epineurium of the nerve sheath but this theory was later discarded as the ultra-scans of nerve sheath showed it as a highly selective barrier. Latest studies demonstrate that PNI occurs 
through various molecular interactions between tumor cells and nerve [6].

There is a wide variation in reported incidence of perineural invasion for oral squamous cell carcinoma, with reportage from as low as $2 \%$ to as high as $80 \%$ [7]. Various features of tumors seem to be related to the incidence of PNI. They include tumor thickness (depth of invasion), tumor differentiation and propensity for lymph node metastasis. Varsha, et al. [5] reported presence of perineural invasion in $40 \%$ cases. They didn't find any particular association of frequency of perineural invasion with tumor size. However, they did find a higher incidence of PNI when the neck lymph nodes were positive for the disease [5]. Rahima B, et al. [8] in a retrospective study of 101 patients found a strong correlation between the depth of invasion by the tumor and PNI and stated that with increase in thickness of the tumor the chance of malignant cells to enter into the nerve fibers increases [8]. Strong relationship between PNI and lymph node metastasis has also been reported by multiple authors [9-12].

Incidence for PNI in our group of patients was found to be $22.03 \%$. No significant was found with either age and gender. While most of the cases with PNI in our group were reported from tongue, site was not identified as statistically significant in our group of patients. Similarly grade and size of the tumor were also found insignificant variable for PNI though 10 of the 13 tumors were in T3 category. We did however find statistically significant relation between PNI and lymph node metastasis which concurs with literature mentioned above. Oral cavity tumors with PNI are prone to neck recurrence [13]. Nair, et al [14] in a retrospective analysis of 1524 patients found higher recurrence in neck node negative patients with PNI [14]. Size of the nerve involved in PNI is also assumed to have an association with recurrence. Aivazian, et al. [15] has shown that PNI in smaller nerves $<1 \mathrm{~mm}$ was not associated with recurrence whereas nerves $>1 \mathrm{~mm}$ in size was significantly associated with local recurrence $(p=0.047)$ [15]. In our data, strong association was found between PNI and risk of recurrence. We however did not find any significant impact of the size of the nerve involved or number of tumor foci around the nerve upon the risk of recurrence.

In a study by Jardim, et al. [16] of 142 patients with SCC of tongue and floor of the mouth, the overall survival was negatively influenced by various variables including advance $\mathrm{T}$ stage and $\mathrm{N}$ stage, more than 2 clinically positive nodes, extra capsular spread, tumor thickness, PNI and LVI [16]. Similarly, most other studies have also shown PNI to different extent, associated with disease recurrence increased risk of regional and distant metastasis and overall decrease in 5-year survival $[17,18]$.

\section{Conclusion}

Majority of studies conclude that PNI is an independent prognostic factor for locoregional control of disease. It may also have an impact upon Overall and disease-free survival of the patients with oral squamous cell carcinoma.

\section{Acknowledgement}

None.

\section{Conflict of Interest}

The authors declare no conflict of interest.

\section{References}

1. Shah JP, Gil Z (2009) Current concepts in management of oral cancer-surgery. Oral Oncol 45(0): 394-401.

2. Attar E, Dey S, Hablas A, Seifeldin IA, Ramadan M, et al. (2010) Head and neck cancer in a developing country: A population-based perspective across 8years. Oral Oncol 46(8): 591-596.

3. Warnakulasuriya S (2009) Global epidemiology of oral and oropharyngeal cancer. Oral Oncol 45(4-5): 309-316.

4. Ayala G, Liebig C, Wilks JA, Albo D, Berger DH (2009) Perineural invasion in cancer. Cancer 115(15): 3379-3391.

5. Varsha BK, Radhika MB, Makarla S, Kuriakose MA, Kiran GS, et al. (2015) Perineural invasion in oral squamous cell carcinoma: Case series and review of literature. J Oral Maxillofac Pathol 19(3): 335-341.

6. Keerthi R, Dutta A, Agarwal S, Kani V, Khatua A (2018) Perineural Invasion of Oral Squamous Cell Carcinoma: A New Hurdle for Surgeons. J Maxillofac Oral Surg 17(1): 59-63.

7. Binmadi NO, Basile JR (2011) Perineural invasion in oral squamous cell carcinoma: A discussion of significance and review of the literature. Oral Oncol 47(11): 1005-1010.

8. Rahima B, Shingaki S, Nagata M, Saito C (2004) Prognostic significance of perineural invasion in oral and oropharyngeal carcinoma. Oral Surg Oral Med Oral Pathol Oral Radiol Endod 97(4): 423-431.

9. Tai SK, Li WY, Yang MH, Chang SY, Chu PY, et al. (2012) Treatment for T1-2 oral squamous cell carcinoma with or without perineural invasion: neck dissection and postoperative adjuvant therapy. Ann Surg Oncol 19(6): 1995-2002.

10. Tai SK, Li WY, Yang MH, Chu PY, Wang YF (2013) Perineural invasion in T1 oral squamous cell carcinoma indicates the need for aggressive elective neck dissection. Am J Surg Pathol 37(8): 1164-1172.

11. Chatzistefanou I, Lubek J, Markou K, Ord RA (2017) The role of perineural invasion in treatment decisions for oral cancer patients: A review of the literature. J Cranio-Maxillo-Facial Surg 45(6):821-825

12. Matsushita Y, Yanamoto S, Takahashi H, Yamada S, Naruse T, et al. (2015) Head and Neck Oncology A clinicopathological study of perineural invasion and vascular invasion in oral tongue squamous cell carcinoma. Int J Oral Maxillofac Surg 44(5): 543-548.

13. Gaddikeri S, Bhrany A, Anzai Y (2014) Perineural Invasion of Skin Cancers in the Head and Neck: An Uncommon Phenomenon Revisited. Otolaryngology 04(03): 1-6

14. Nair D, Mair M, Singhvi H, Mishra A, Nair S, et al. (2018) Perineural invasion: Independent prognostic factor in oral cancer that warrants adjuvant treatment. Head Neck 40(8):1780-1787.

15. Aivazian K, Ebrahimi A, Low THH, Gao K, Clifford A, et al. (2015) Perineural invasion in oral squamous cell carcinoma: Quantitative subcategorisation of perineural invasion and prognostication. J Surg Oncol 111(3): 352-358.

16. Jardim JF, Francisco ALN, Gondak R, Damascena A, Kowalski LP (2015) Prognostic impact of perineural invasion and lymphovascular invasion in advanced stage oral squamous cell carcinoma. Int J Oral Maxillofac Surg 2015 44(1): 23-28. 
17. Woolgar JA (2006) Histopathological prognosticators in oral and oropharyngeal squamous cell carcinoma. Oral Oncol 42(3): 229-239.
18. Tadbir AA, Ashraf MJ, Sardari Y (2009) Prognostic significance of stromal eosinophilic infiltration in oral squamous cell carcinoma. J Craniofac Surg 2009 20(2): 287-289. 